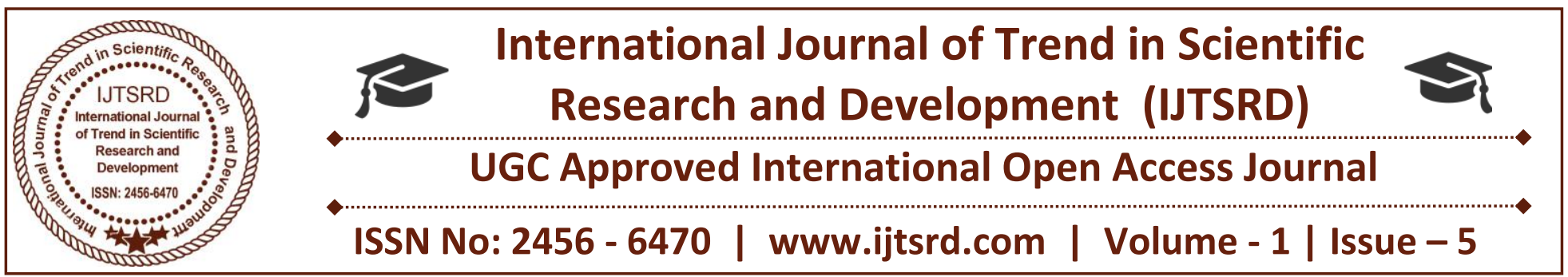

\title{
Challenges of E-commerce
}

\author{
Ms. Ashwini Jagdale \\ Dr. D. Y. Patil SCS College, Akurdi, \\ Pune, Maharashtra, India
}

\author{
Ms. Ashwini Rupnawar \\ Dr. D. Y. Patil SCS College, Akurdi, \\ Pune, Maharashtra, India
}

\begin{abstract}
E-commerce is an facility for each and every user buying and selling product through the internet. By using E-commerce we can manage everything in our time. Every person/user can handle different transaction like E-payment-billing, Mobile banking, Net banking-learning,_E-insurance, etc. In India Ecommerce technology is increased because of wide range of products and minimum price wide range of suppliers and customers internet. Electronic Commerce is enabling the customer to have an

E-commerce includes a different variety of customer activities. These include different types of transactions like B2B (Business-to Business), B2C (Business-to-Consumer), C2C (Consumer-toConsumer), C2B (Consumer-to-Business). Electronic transactions have been around for quite some time in the form of Electronic Data Interchange or EDI. Electronic Data Interchange (EDI) is the computer-tocomputer exchange of business documents in a standard electronic format between business partners.
\end{abstract} increasing say in what products are made, how products are made and how services are delivered. Through the E-commerce we can achieve greater economic efficiency (lower cost) and more rapid exchange (high speed, accelerated, or real-time interaction.

This paper gives an overview of the future of ECommerce and discusses the scope, challenges, Types of E-commerce, Uses, Advantages and disadvantages of E-Commerce. Also use of EDI. We also find out to help future growth of Indian e-commerce. This paper also represents evaluation of internet user's.

Keywords: E-commerce, Scope, Uses, Challenges, Future Enhancement, EDI

\section{Introduction}

E-commerce is a business model or a larger business model that allows us or individuals through the electronic network and is usually the different type of business in the internet. E-commerce creates new relationships with website and network activity.

\section{Definition}

Electronic commerce or ecommerce is a term for any type of business that involves the transfer of information across the Internet. Ecommerce allows consumers to electronically exchange goods and services with no barriers of time or distance. Ecommerce is the use of electronic communications and digital information processing technology in business transactions to create, transform, and redefine relationships for value creation between or among organizations, and between organizations and individuals.

\section{Literal Surveys of E-commerce Challenges}

E-commerce was introduced 40 years ago .Since the late 1970s saw the development, prior to anything resembling Internet commerce, of method's for businesses to process their transactions with each other using electronic means. Strictly speaking, a range of the technologically-driven innovations of the 1980s, such as ATMs, can also be considered as parts 
of the history of e-commerce, albeit one without the same access to computing on the part of consumers as was enjoyed by the large businesses serving them.

The modern phase of e-commerce was marked by a shift to a more open source, os commerce approach, as began with the 1990 creation of a web browser for searching the World Wide Web, though Internet commerce as such only became allowable in 1991.

\section{Scope Of the E-commerce:}

The scope of e-Commerce business is turning out to be more famous day-after-day according to the market demand. Another significant contributor to the growth of e-Commerce in India in the future is the e-tailing industry which largely deals in providing jewellery, apparel and kitchen appliances online. Websites like Flipkart, Myntra, Amazon, Snapdeal, Jabong, etc. are all examples of the enormous success of ecommerce in India. As India has been the heart of the ecommerce market in 2016 with the tremendous growth of $70 \%$. The consumer base is expected to hit 100 million in 2017, and this ensures that any ecommerce venture would soon be the best business in India, as far as profits and growth are concerned.

\section{EDI (Electronic Data Interchange)}

Electronic data interchange (EDI) is the computer-tocomputer exchange of business documents between companies. EDI replaces the faxing and mailing of paper documents.

EDI documents use specific computer record formats that are based on widely accepted standards. However, each company will use the flexibility allowed by the standards in a unique way that fits their business needs.

In EDI we are sending application that application converted into Standard EDI format and this format is sending through VAN, and stored and resend to EDI fromat.EDI convert this message to receiver.

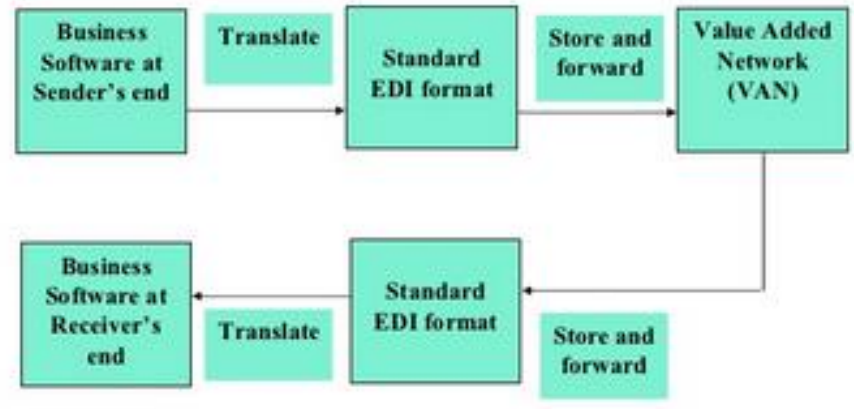

A value-added network (VAN) is a private network provider (sometimes called a turnkey communications line) that is hired by a company to facilitate electronic data interchange (EDI) or provide other network services

\section{Types of E-Commerce}

\section{1:B2B(Business-to-Business):}

When the business transaction takes place between two businesses through the electronic medium, it is called B2B commerce. This model defines that Buyer and seller are two different entities. It is similar to manufacturer issuing goods to the retailer or wholesaler.

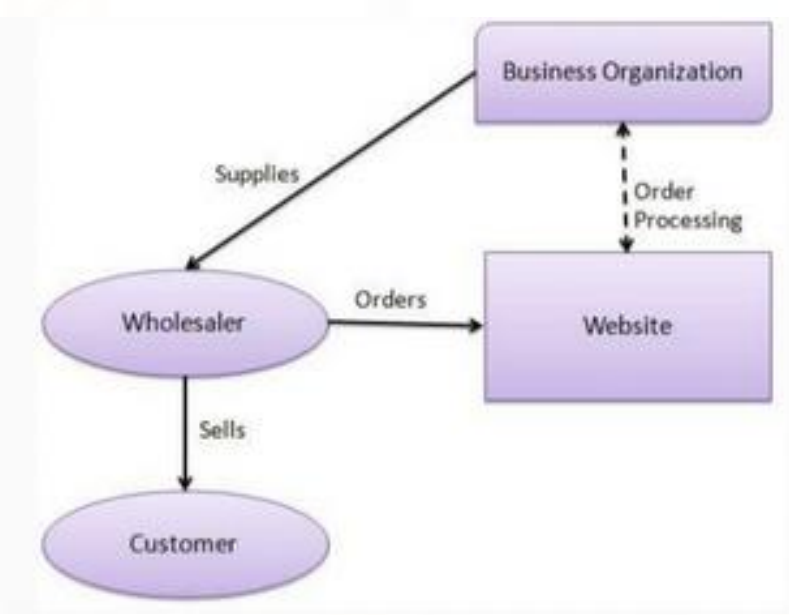

\section{2:B2C(Business-to-Consumer):}

When the business transaction takes place between business and Consumer through the electronic medium, it is called B2C Transation. B2c is the Interface between the company and consumers. 


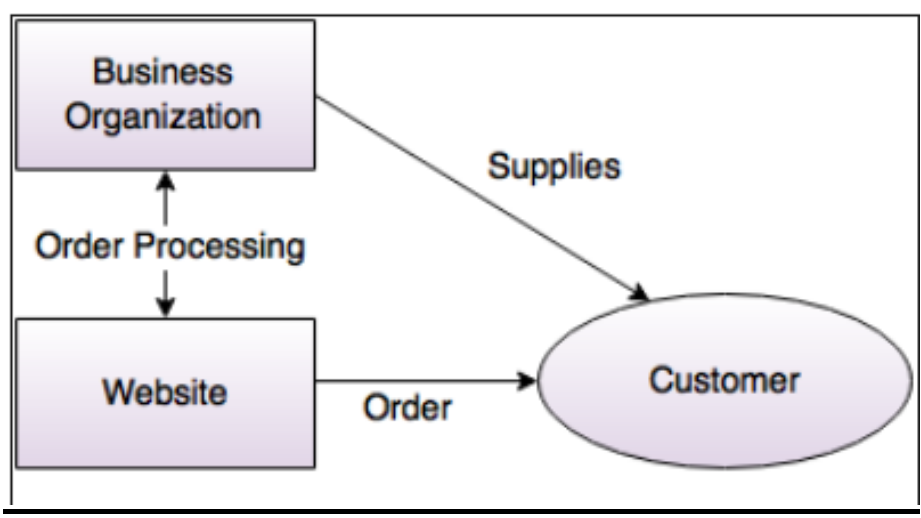

\section{3:C2C(-Consumer-to-Consumer):}

When the business transaction takes place between Consumer to Consumer through the electronic medium, it is called $\mathrm{C} 2 \mathrm{C}$ transaction. There are many sites offering free classifieds, auctions, and forums where Consumer can buy and sell Products through online. eBay's auction service is a great example of where person-to-person transactions take place every day since 1995.

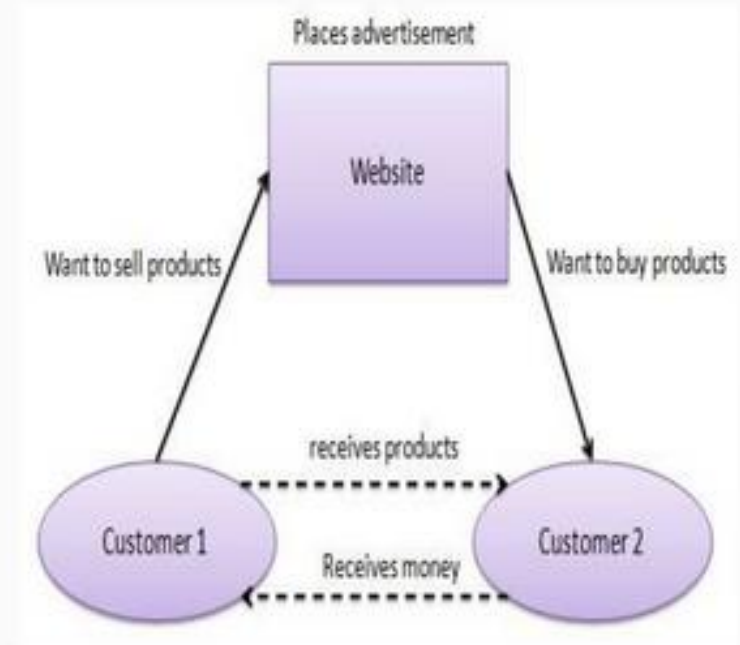

\section{4:C2B(Consumer-to-Business):}

When the business transaction takes place between Consumer to Business through the electronic medium, it is called $\mathrm{C} 2 \mathrm{~B}$ transaction.eg:E-banking

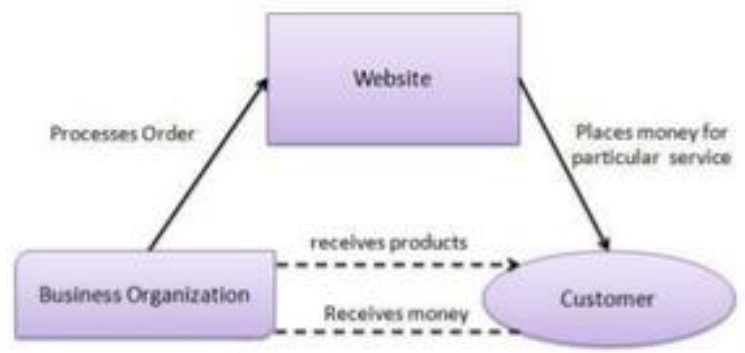

\section{Uses of E-commerce}

E-Commerce can improve your business processes and information flows by enabling you to communicate with other businesses.

$>$ Using your computer, you can connect to the bank's computer system via the internet and control your daily financial dealing from home. It reduces the staff and building of banks. May customers pay their bills from their bank accounts using this facility.

It has become very easy from the people to shop from home using internet. Different manufacturers present their product s on the internet. People can browse the website, place an order and even make a payment using different card. It has made shopping very easy.

E-commerce is playing an important part to market and advertise products all over the world. The use of popular websites can be an effective way of introducing a product to the customers.

Businessmen can interact with their customers using the internet. They can discuss different issues about their products. They can also deal with their complaints and provide different services to them.

\section{Advantages of E-Commerce}

$>$ Faster buying/selling procedure, as well as easy to find products.

Buying/selling 24/7.

More reach to customers, there is no theoretical geographic limitations.

Low operational costs and better quality of services.

$>$ No need of physical company set-ups.

$>$ Easy to start and manage a business.

$>$ Customers can easily select products from different providers without moving around physically. 


\section{Disadvantages of Ecommerce}

Any one, good or bad, can easily start a business. And there are many bad sites which eat up customers' money.

$>$ There is no guarantee of product quality.

$>$ Mechanical failures can cause unpredictable effects on the total processes.

$>$ As there is minimum chance of direct customer to company interactions, customer loyalty is always on a check.

$>$ There are many hackers who look for opportunities, and thus an ecommerce site, service, payment gateways, all are always prone to attack.

$>$ The customer has to wait for delivery of their product.

$>$ Perishable goods bought online can get spoiled during delivery.

$>$ It is difficult to know when an online site is safe to use.

\section{Challenges of E-commerce}

There are different issues related to e-commerce like privacy and security. There is no protection offered either by Website or outside watchdogs against hazard created by exploiting one's privacy.

Tax rate system of Indian market is another factor for lesser growth rate of e-Commerce in India in comparison to other developed countries like USA and UK. In those countries, tax rate is uniform for all sectors, whereas tax structure of India varies from sector to sector. This factor creates accounting problems for the Indian online business companies.

$>$ Consumers are physically attractable for buying any products. They first see the products and touch them before buying. so they are more challenging to the companies.

$>$ Logistics failure in any area can mean detrimental damage to a startup's future and can hurt the brand overall. Add to this the need for a guaranteed return policy. Getting this right is a challenge.

$>$ If we place an online order, we get a call from that organization to ask about our information. Clearly the address is not sufficient. This is because there is some standardization in the addresses are written.

\section{Future Enhancement}

Social networking sites are very popular medium for communication, so that the consumers get alert about their post.

> Social networking Sites like Facebook, LinkedIn, Twitter, Google+. Increase the advertising \& promotions.

$>$ We can increase the security and privacy between different transactions by creating that data in encryption format.

$>$ All the Activities in all the fields will become fully atomized.

Maximum use of advanced technology, with the use of various advanced apps.(Smartphone, Tablets)

$>$ Maximum use of E-banking.

$>$ The use of SEO (Search Engine Optimizer) will fast the process of marketing to attract maximum customers in less time.

\section{Concluding Remark}

The e-commerce market in India is estimated to grow from $\$ 10$ billion every year to between $\$ 70-260$ billion every year by 2025 .

It is also estimated that the e-commerce market is about $57 \%$ from small towns and the balance from the largest metros. The most popular use of e-commerce is on travel websites, which is done by about $70 \%$ of all e-commerce consumers in India. There are challenges to e-commerce companies operating in India - including some reluctance of consumers to pay for goods or services online. Some companies are trying to get around this problem by providing cashon-delivery as a service to their consumers.

E-commerce creates new opportunities for business; it also creates new opportunities for education and academics. It appears that there is tremendous potential for providing e-business education.

As discussed earlier about the different media of ecommerce such as TV, PC or Mobile these new media will be a major preoccupation for marketers over the few years that especially how to combine them within an integrated bricks and clicks marketing mix. 


\section{REFERENCES}

1) Diana Oblinger(2001); Will E-business Shape the Future of Open and Distance Learning?; Open Learning; Vol. 16, No. 1, 2001; pp.9-25.

2) Elizabeth Goldsmith and Sue L.T. McGregor(2000); E-commerce: consumer protection issues and implications for research and education; J Consumer Studies \& Home Economics; Vol.24, No.2, June 2000, pp.124-127.

3) Patric Barwise(2001); TV, PC or Mobile? Future media for consumer e-commerce; Business strategy review; Vol.12, issue 1; 2001; pp.35-42.

4) Prithviraj Dasgupta and Kasturi Sengupta(2002); E-Commerce in the Indian Insurance Industry; Electronic Commerce Research; Vol.2, 2002; pp.43-60.

5) Zabihollah Rezaee, Kenneth R. Lambert and W. Ken Harmon(2006); Electronic Commerce Education: Analysis of Existing Courses; Accounting Education:An International Journal; Vol. 15, No. 1 March 2006; pp73-88.

6) eBay PowerSeller Practices for Dummies by Marsha Collier, 